Nota Cientifica

\title{
EFEITO DE ADJUVANTES ADICIONADOS À CALDA HERBICIDA CONTENDO GLYPHOSATE ${ }^{1}$
}

LEANDRO VARGAS ${ }^{2}$; NILSON G. FLECK ${ }^{3}$; MARCOS M. DA CUNHA ${ }^{2}$ e RIBAS A. VIDAL ${ }^{4}$

\section{RESUMO}

Tentativas de aumentar a fitotoxicidade do herbicida glyphosate através da adição de ácido e/ou de sulfato de amônio à calda tem sido promissoras. A adição dessas substâncias otimiza as propriedades químicas da calda herbicida, superando efeitos negativos do $\mathrm{pH}$ elevado e de ions nela presentes. O objetivo desse trabalho foi investig ar o efeito da adição de ácido sulfúrico e/ou de sulfato de amônio à calda herbicida, sobre a eficiência do glyphosate misturado em diluente com al to $\mathrm{pH}$ e te ores elevados de sais. Os tratamentos envolveram cinco doses de glyphosate (variáveis de 180 a $540 \mathrm{~g} / \mathrm{ha}$ i.a.) diluídas em água destilada e, mais glyphosate a $270 \mathrm{~g} / \mathrm{ha}$ misturado às águas minerais Fonte Azul e Fonte Ijuí e m presença de ácido sulfúrico (0,5 1/ha) e/ou sulfato de amônio $(2,5 \mathrm{~kg} / \mathrm{ha})$. A fitotoxicidade foi avaliada aos 7, 17 e 27 dias após as aplicações do herbicida sobre a aveia preta. Os resultados demonstraram que a aveia-preta é muito suscetível à ação de glyphosate, mesmo aplicado a $270 \mathrm{~g} / \mathrm{ha}$, independente da água utilizada ou da adição de adjuvantes e, que a adição de ácido sulfúrico e/ou de sulfato de amônio à calda não alterou a atividade do herbicida.

Pa lavras chave: Avena strigosa, $\mathrm{pH}$, adjuvante, ácido sulfurico, sulfato de amônia.

\section{ABSTRACT \\ Effect of adjuvants added to herbicide spray containing glyphosate.}

Attempts to increase phytotoxicity of ammonium sulphate addition to herbicide spray, on gly pho sate herbicide through addition of acid and/or of ammonium sulphate to the spray solution have been promising. Addition of these substances optimize chemical properties of the herbicide spray, overcoming negative effects of high $\mathrm{pH}$ and of ions present in it. The objective of this research was to investigate the effect of sulphuric acid and/or of the efficiency of glyphosate mixed in diluents with high $\mathrm{pH}$ and high salts content. Glyphosate treatments consisted of five rates (variables from 180 to $540 \mathrm{~g} / \mathrm{ha}$ a.e.), diluted in distilled water, and also glyphosate at $270 \mathrm{~g} / \mathrm{h}$ a a.e. mix ed in the mineral waters Fonte Azul and Fonte Ijuí. To this herbicide rate, it was added $0,51 /$ ha of sulphuric

1Recebido para publicação em 26/09/96 e na forma revisada em 15/10/97.

2Eng. Agr., Aluno do Programa de Pós-Graduação em Agronomia, Faculdade de Agronomia da UFRGS, Porto Alegre, RS.

3Eng. Agr., Ph. D., Prof. Aposentado do Depto. de Plantas de Lavoura, Fac. de Agronomia da UFRGS. Cx. Postal 776, CEP 90001-970, Porto Alegre, RS. Bolsista do CNPq. 4Eng. Agr., Ph. D., Prof. Adjunto do Depto. de Plantas de Lavoura, Fac. de Agronomia da UFRGS. 
acid and/or 2,5 kg/ha of ammonium sulphate, whose treatments were sprayed over oat plants. Herbicide toxicity was evaluated at 7, 17, and 27 days after applications. Results showed that oats was very susceptible to glyphosate action, even when applied at $270 \mathrm{~g} / \mathrm{ha}$, independent of water

\section{INTRODUÇÃO}

Em consonância com as necessidades conservacionistas dos métodos de semeadura direta ou de preparo mínimo do solo, os sistemas de produção de culturas requerem aplicações mais eficientes de herbicidas de pós-emergência em substituição ao emprego de cultivos mecânicos (Bryson et al., 1994). Tentativas em manter ou aumentar a fitotoxicidade do glyphosate pela redução do volume do diluente, adição de ácido sulfúrico ou sulfato de amônio à calda herbicida tem-se mostrado práticas promissoras. Essas modificações na aplicação têm permitido reduções na dose herbicida, resultando em diminuição do custo, enquanto mantém um nível de controle eficiente das plantas daninhas (Carlson \& Burnside, 1984).

Ácidos e adubos nitrogenados são referidos como substâncias adjuvantes capazes de aumentar a eficiência de vários herbicidas de pós-emergência. A adição de determinados ácidos à solução contendo glyphosate supera a perda de eficiência desse herbicida causada por água 'dura' (Buhler \& Burnside, 1983b). Também há evidência de que a fi to to xi cidade do glyphosate é af etada por mudanças no pH da solução de pulverização (Wills $\&$ Mcwhorter, 1985).

As propriedades físico-químicas e a atividade dos herbicidas podem ser alteradas com a redução do pH da calda (McCormick, 1990). A acidificação da calda reduz a dissociação das moléculas; as sim, herbicidas dissolvidos em condições de baixo pH são absorvidos com maior facilidade pelas plantas devido às moléculas used or adjuvantes added. It is concluded that addition of sulphuric acid and/or of ammonium sulphate to spray solution do not increase herbicide activity of glyphosate.

Key words: Avena strigosa, $\mathrm{pH}$, additive, sulfuric acid, Ammonium sulphate.

encontrarem-se na for ma não-dissociada (Wanamarta \& Penner, 1989). Aumentando o pH de uma solução contendo glyphosate, verifica-se a oc or rência de sucessiva desprotoni zação da molécula herbicida. $\mathrm{O}$ pH da solução mostra influência sobre a cutícula e a ionização das moléculas do herbicida, o que aumenta a absorção do produto (Wanamarta \& Penner, 1989).

$\mathrm{O}$ uso de gases pressurizadores, como ar ou $\mathrm{N}_{2}$, nos pulverizad ores costais us ualmente empregados em pesquisas com herbicidas, tem mostrado pouco efeito sobre o $\mathrm{pH}$; já o uso de $\mathrm{CO} 2$ pode ocasionar sua reação com a água, resultando em decréscimo do pH pela formação de ácido carbônico no meio (Leif 111 \& Oelke, 1990).

Combinações de glyphosate com nitrogênio líquido aumentou o controle de plantas de centeio (Sandberg et al., 1978).

Dentro da faixa de $\mathrm{pH}$ fisioló gico (de 5 a 8), o glyphosate está carregado negativamente, existindo tanto como ânion monovalente como bivalente. Devido às múltiplas cargas negativas existentes sobre a molécula do glyphosate, ele pode formar complexos estáveis (quelatos) com cátions bivalentes e trivalentes em solução aquosa (Mervosh \& Balke, 1991). 0 pH da solução e os íons presentes na calda também influenciaram na fitotoxicidade do herbicida sethoxydim, sendo que sódio e cálcio mostraram-se antagônicos ao herbicida em pH acima de 7 (Nalewaja et al., 1994). Esse fato pode ser devido à protonação das molécu las do sethoxydim em baixo $\mathrm{pH}$, o que facilita sua absorção (Nalewaja et al., 1994; McMullan, 1996). Para superar esse efeito, ou em parte contorná-lo, a adição de ácidos e/ou de 
adubos nitrogenados à calda pode resultar em aumentos na fitotoxicidade de certos herbicidas.

Visando aumentar a ação herbicida, o ácido sulfúrico tem-se mostrado eficiente quando adicionado à água de poços artesianos (Buhler \& Burnside, 1983b; Carlson \& Burnside, 1984). 0 sulfato de amônio também pode neutralizar o antagonismo desses cátions à plena atividade do glyphosate (Nalewaja \& Matysiak, 1993a). Adubos nitrogenados, como nitrato de amônio e sulfato de amônio, também possuem potencial para alterar o pH da solução (McCormick, 1990).

$\mathrm{O}$ sinergismo ou o antagonismo a atividade fitotóxica do glyphosate, provocada pela adição de diferentes substâncias, envolvem a resposta do herbicida ao $\mathrm{pH}$, a sua complexação com íons metálicos, efeitos da concentração do herbicida e do surfatante e diferenças de retenção da pulverização por distintas espécies vegetais (Nalewaja et al., 1994). A importância do uso de adjuvantes em ot imizar a atividade de muitos compos tos herbicidas de aplicação em pós-emergência at ualmente está be m recon hecida, e pode representar economia na aplicação pela possibilidade do uso de doses reduzidas (Sherrick et al., 1986). Cabe ressaltar, que a ad ição de substâncias ácidas no tanque do pulverizador possa provocar corrosão em alguns componentes do equipamento.

O objetivo desse trabalho foi investigar o efeito da adição de ácido sulfúrico e/ou de sulfato de amônio à calda herbicida sobre a eficiência de glyphosate quando aplicado em diluentes apresentando alto $\mathrm{pH}$ e/ou contendo teores elevados de sais (águas minerais).

\section{MATERIAL E MÉTODOS}

O experimento foi realizado na Estação Experimental Agronômica da Universidade Federal do Rio Grande do Sul (EEA/UFRGS), localizada no mu ni cí pio de Eldora do do Sul, RS, re gião fisiográfica da Depressão Central do Estado do Rio
Grande do Sul.

$\mathrm{O}$ delineamento experimental utilizado foi blocos casualizados, com quatro repetições. A área total de cada parcela foi $12,5 \mathrm{~m}^{2}(2,5 \times 5 \mathrm{~m})$. Os tratamentos testados estão listados na Tabela 1 e a ordem de adição dos componentes no tanque foi: sulfato de amônio, ácido sulfúrico e, por último, o herbicida glyphosate. Após a adição de cada substância, realizou-se forte agitação para se obter uma mistura homogênea. De cada tratamento, retirou-se uma amostra, com aproximadamente 50 $\mathrm{ml}$ de solução, para medição do pH em laboratório (Tabela 2). Para avaliar o efeito dos tratamentos utilizou-se aveia-preta "Comum RS" (Avena strigosa Schreb.) como espécie alvo.

A aplicação dos tratamentos oco rreu quando a maioria das plantas de aveia-preta encontravam-se no estádio de cinco a seis folhas. Para tal, foi utilizado pulverizador costal de prec isão, pressurizado com gás ni trogênio, mantendo-se a pressão constante durante as aplicações, a qual esteve fixada em $140 \mathrm{kPa}$. O pulverizador foi equipado com bicos de jato plano da série 110.03 e, dessa forma, proporcionando um volume de aplicação de 200 1/ha.

As avaliações dos efeitos herbicidas foram realizadas aos 7, 17 e 27 dias após a pulverização dos tratamentos (DAT), (Tabela 2). A avaliação dos efeitos foi realizada visualmente, utilizando-se escala percentual, onde nota zero significou ausência de dano aparente à aveia e nota cem representou morte completa das plantas. Tais avaliações foram realizadas por três avaliadores independentes, sendo as notas somadas e calculadas as respectivas médias. Posteriormente, as médias foram submetidas à análise de variância e, quando constatada significância estatística, comparou-se as médias através do teste de Duncan ao nível de 5\% de probabilidade.

Também foram realizadas medições laboratoriais do $\mathrm{pH}$ das águas us ad as como diluentes do herbicida e dos aditivos nelas misturados, para verificar o ef ei to de ss as

Planta Daninha, v. 15, n. 2, 1997. 
substâncias sobre o $\mathrm{pH}$ original das águas. Nesse caso, os tratamentos foram diferentes águas contendo glyphosate nas concentrações de 0,125 ; 0,25: 0,$5 ; 1$ e $2 \%$ (v/v) ou sulfosato a 0,$5 ; 1$ e, $2 \%$ $(\mathrm{v} / \mathrm{v})$; sulfato de amônio a 1,25 e $2,5 \%(\mathrm{p} / \mathrm{v})$; glyphosate a 0,$5 ; 1$ e $2 \%(\mathrm{v} / \mathrm{v})$ mais sulfato de amônio a 2,5\% (p/v) e, esse último, mais ácido sulfúrico a $0,25 \%(\mathrm{v} / \mathrm{v})$ conforme mostrado na Tabela 3.

TABELA 1. Tratamentos contendo herbicida glyphosate, com ou sem uso de aditivos, ap li ca do s sobre aveia-preta (Avena strigosa), EEA/UFRGS, Eldorado do Sul, RS, 1995.

\begin{tabular}{|c|c|c|}
\hline $\begin{array}{c}\text { Água } \\
\text { diluente }\end{array}$ & $\begin{array}{c}\text { Doses } \\
\text { (g/ha i.a.) }\end{array}$ & Adjuvantes \\
\hline Destilada & $180(0,125 \%)^{1}$ & nenhum \\
\hline Destilada & $270 \quad(0,25 \%)$ & nenhum \\
\hline Destilada & $360 \quad(0,5 \%)$ & nenhum \\
\hline Destilada & $450 \quad(1 \%)$ & nenhum \\
\hline Destilada & $540 \quad(2 \%)$ & nenhum \\
\hline Destilada & 270 & ácido sulfúrico ${ }^{2}$ \\
\hline Destilada & 270 & sulfato de amônio ${ }^{3}$ \\
\hline Destilada & 270 & ác. sulfúrico + sulf. amônio \\
\hline Fonte Azul & 270 & nenhum \\
\hline Fonte Azul & 360 & nenhum \\
\hline Fonte Azul & 450 & nenhum \\
\hline Fonte Azul & 270 & ácido sulfúrico \\
\hline Fonte Azul & 270 & sulfato de amônio \\
\hline Fonte Azul & 270 & ác. sulfúrico + sulf. amônio \\
\hline Fonte Ijuí & 270 & nenhum \\
\hline Fonte Ijuí & 360 & nenhum \\
\hline Fonte ljuí & 450 & nenhum \\
\hline Fonte Ijuí & 270 & ácido sulfúrico \\
\hline Fonte ljuí & 270 & sulfato de amônia \\
\hline Fonte Ijuí & 270 & ác. sulfúrico + sulf. amônio \\
\hline Testemunha & 0 & nenhum \\
\hline
\end{tabular}

\section{RESULTADOS E DISCUSSÃO}

$\mathrm{Na}$ avaliação realizada aos 7 DAT, os maiores graus de fitotoxicidade, em valores absolutos, foram constatados nos tratamentos água destilada contendo 360; 450 ou 540 g/ha i.a. de glyphosate e água Fonte Ijuí contendo 380 ou 450 g/ha i.a. de glyphosate. Por outro lado, o tratamento água Destilada com 270 g/ha i.a. de glyphosate, mais ácido sulfúrico propiciou a menor fitotoxicidade em valor absoluto (Tabela 2). Os demais tratamentos apresentaram posição intermediária.

Planta Daninha, v. 15, n. 2, 1997. 
TABELA 2. Efeitos de diferentes tipos de água e aditivos na fitotoxicidade do herbicida glyphosate em aveia-preta, EEA/UFRGS, Eldorado do Sul, RS,1995.

\begin{tabular}{|c|c|c|c|c|c|c|}
\hline \multirow{2}{*}{\multicolumn{2}{|c|}{$\begin{array}{l}\text { TRATAMENTOS } \\
\begin{array}{l}\text { dose de glyphosate } \\
\text { e aditivos (l/ha p.c.) }\end{array} \\
\end{array}$}} & \multirow[b]{2}{*}{$\begin{array}{l}\text { g/ha } \\
\text { (i.a.) } \\
\end{array}$} & \multirow[b]{2}{*}{$\begin{array}{l}\text { pH da } \\
\text { calda }\end{array}$} & \multicolumn{3}{|c|}{ Fitotoxicidade (\%) } \\
\hline & & & & 7 DAT $^{1}$ & 17 DAT & 27 DAT \\
\hline & 0,50 & 180 & 4.37 & $22 a b^{4}$ & $86 \mathrm{c}$ & $93 \mathrm{a}$ \\
\hline & 0,75 & 270 & 4.19 & $21 \mathrm{ab}$ & $93 \mathrm{ab}$ & $98 \mathrm{a}$ \\
\hline Água & 1,00 & 360 & 4.15 & $29 \mathrm{a}$ & $96 a b$ & $99 \mathrm{a}$ \\
\hline \multirow[t]{5}{*}{ destilada } & 1,25 & 450 & 4.28 & $31 \mathrm{a}$ & $97 \mathrm{ab}$ & $99 \mathrm{a}$ \\
\hline & 1,50 & 540 & 4.35 & $30 \mathrm{a}$ & 98 a & $100 \mathrm{a}$ \\
\hline & $0,75+$ ácido $^{2}$ & 270 & 0.51 & $19 \mathrm{~b}$ & $91 \mathrm{bc}$ & $97 \mathrm{a}$ \\
\hline & $0,75+$ sulfato $^{3}$ & 270 & 4.05 & $22 \mathrm{ab}$ & $92 a b c$ & $98 \mathrm{a}$ \\
\hline & $0,75+$ ácido + sulfato & 270 & 0.57 & $25 \mathrm{ab}$ & $92 \mathrm{abc}$ & $98 \mathrm{a}$ \\
\hline & 0,75 & 270 & 5.16 & $23 a b$ & $94 a b$ & 98 a \\
\hline Água & 1.00 & 360 & 5.06 & $29 \mathrm{a}$ & $96 a b$ & 99 a \\
\hline Fonte & 1,25 & 450 & 4.83 & $29 \mathrm{a}$ & $95 \mathrm{ab}$ & 99 a \\
\hline \multirow[t]{3}{*}{ Ijuí } & $0,75+$ ácido & 270 & 0.63 & $23 \mathrm{ab}$ & 92 abc & $98 \mathrm{a}$ \\
\hline & $0,75+$ sulfato & 270 & 5.29 & $23 \mathrm{ab}$ & $94 \mathrm{ab}$ & 99 a \\
\hline & $0,75+$ ácido + sulfato & 270 & 0.96 & $21 \mathrm{ab}$ & $93 \mathrm{ab}$ & $99 \mathrm{a}$ \\
\hline & 0,75 & 360 & 5.30 & $24 a b$ & $94 \mathrm{ab}$ & 99 a \\
\hline Água & 1,00 & 360 & 5.29 & $22 \mathrm{ab}$ & $95 \mathrm{ab}$ & 99 a \\
\hline Fonte & 1,25 & 450 & 5.10 & $26 a b$ & $97 \mathrm{ab}$ & 99 a \\
\hline \multirow[t]{5}{*}{ Azul } & $0,75+$ ácido & 270 & 0.69 & $25 \mathrm{ab}$ & $96 a b$ & 99 a \\
\hline & $0,75+$ sulfato & 270 & 5.28 & $26 \mathrm{ab}$ & $93 \mathrm{ab}$ & 99 a \\
\hline & $0,75+$ ácido + sulfato & 270 & 1.01 & $26 \mathrm{ab}$ & $94 \mathrm{ab}$ & $99 \mathrm{a}$ \\
\hline & Testemunha & - & - & $0 \mathrm{c}$ & $0 \mathrm{~d}$ & $0 \mathrm{~b}$ \\
\hline & C.V. $(\%)$ & - & - & 23,0 & 4,5 & 11,6 \\
\hline
\end{tabular}

-pH original: Água destilada 5,19; Água Fonte Ijui 9,66; Água Fonte Azul 9,45.

Dias após tratamento herbicida.

2 Ácido sulfúrico a $0.25 \%(\mathrm{v} / \mathrm{v})$.

${ }^{3}$ Sulfato de amônio a $1.25 \%(\mathrm{p} / \mathrm{v})$.

${ }^{4}$ Médias seguidas de mesma letra, comparadas nas colunas, não diferem estatisticamente pelo teste de Duncan ao nivel de $5 \%$ de probabilidade.

Na segunda avaliação, oco rrida aos 17 DAT, a maior fitotoxicidade foi constatada no tratamento água destilada contendo $540 \mathrm{~g} / \mathrm{ha}$ i.a.de glyphosate; enquanto a menor foi observada em água destilada com $180 \mathrm{~g} / \mathrm{ha}$ i.a. de glyphosate. Esse não diferiu de água destilada com $270 \mathrm{~g} / \mathrm{ha}$ i.a. de glyphosate mais ácido sulfúrico e/ou sulfato de amônio, e nem de água Fonte Ijuí com 270 g/ha i.a. de glyphosate mais ácido sulfúrico. Os demais tratamentos posicionaram-se entre aqueles dois. Na última avaliação, realizada aos 27 DAT, não houve diferença estatística entre os tratamentos herbicidas e a fitotoxicidade manteve-se entre $93 \mathrm{e}$ $100 \%$ para todos eles. 
TABELA 3. Efeitos da adição de glyphosate ou sulfosate, de ácido sulfúrico e de sulfato de amônio sobre o pH de águas de diferentes origens, Faculdade de Agronomia, UFRGS, Porto Alegre, RS, 1995.

\begin{tabular}{|c|c|c|c|c|c|}
\hline Águas diluentes & $\begin{array}{c}\text { Água } \\
\text { destilada }\end{array}$ & Da Guarda & Fonte Azul & Fonte Ijuí & $\begin{array}{c}\text { Fonte } \\
\text { Sarandi } \\
\end{array}$ \\
\hline $\mathrm{pH}$ inicial & 5,3 & 6,6 & 9,4 & 9,4 & 9,8 \\
\hline \multicolumn{6}{|l|}{ Herbicida e/ou aditivos } \\
\hline \multicolumn{6}{|l|}{ Glyphosate } \\
\hline $0,125 \% \mathrm{v} / \mathrm{v}$ & 4,0 & - & 6,7 & 6,3 & 5,8 \\
\hline $0,250 \%$ & 4,1 & - & 5,8 & 5,5 & 5,1 \\
\hline $0,5 \%$ & 3,9 & 4,1 & 4,7 & 5,0 & 4,6 \\
\hline $1 \%$ & 3,8 & 4,0 & 4,7 & 4,5 & 4,3 \\
\hline $2 \%$ & 3,8 & 4,1 & 4,4 & 4,2 & 4,1 \\
\hline \multicolumn{6}{|l|}{ Sulfosate } \\
\hline $0,5 \% \mathrm{v} / \mathrm{v}$ & 3,0 & 3,3 & 4,5 & 4,5 & 4,3 \\
\hline $1 \%$ & 3,0 & 3,3 & 4,4 & 4,1 & 4,0 \\
\hline $2 \%$ & 3,0 & 3,3 & 4,0 & $\underline{3,8}$ & 3,6 \\
\hline \multicolumn{6}{|l|}{ Sulfato de amônio } \\
\hline $1,25 \mathrm{~kg} / \mathrm{ha}(1,25 \% \mathrm{p} / \mathrm{v})$ & 4,5 & - & 7,1 & 7,1 & 7,1 \\
\hline $2,50 \mathrm{~kg} / \mathrm{ha}(2,5 \% \mathrm{p} / \mathrm{v})$ & 4,3 & - & 6,5 & 7, & 6,9 \\
\hline \multicolumn{6}{|l|}{ Glyphosate } \\
\hline $0,5 \%+$ sulfato $^{1}$ & 4,2 & - & 5,2 & 5,0 & 4,8 \\
\hline $1 \%+$ sulfato & 4,2 & - & 4,8 & 4,7 & 4,6 \\
\hline $2 \%+$ sulfato & 4,2 & - & 4,6 & 4,5 & 4,4 \\
\hline $0,5 \%+$ sulfato + ácido $^{2}$ & 2,0 & - & 2,2 & 1,9 & 1,8 \\
\hline $1 \%$ + sulfato + ácido & 1,9 & - & 2,3 & 2,2 & 2,2 \\
\hline $2 \%+$ sulfato + ácido & 2,2 & - & 2,4 & 2,4 & 2,6 \\
\hline
\end{tabular}

${ }^{1}$ Sulfato de amônio a $2,5 \%(\mathrm{p} / \mathrm{v})$.

2 Ácido sulfúrico a $0.25 \%(\mathrm{v} / \mathrm{v})$.

Com relação às doses herbicidas, constatou-se que nos tratamentos com água destilada não ocorreu efeito diferencial de doses aos 7 DAT. Já na segunda avaliação (17 DAT), a dose de $180 \mathrm{~g} /$ ha i.a. de glyphosate foi inferior às demais. Para a dose padrão (270 g/ha i.a. de glyphosate), adição de ácido sulfúrico e/ou de sulfato de amônio não alterou o nível de controle. Contudo, Buhler \& Burnside (1983b) constataram que adição de ácido sulfúrico a 0,25\% (v/v) na calda superou a redução de atividade do glyphosate causada por águas duras, sendo comparável aos resultados obtidos por Thelen et al. (1995). Nesse experimento, acredita-se que as águas testadas não tenham exercido efeito negativo sobre a ação do glyphosate, tendo em vista que adição de ácido não afetou a atividade do herbicida. Isso decorre do fato que ao se usar as águas minerais Fonte Ijuí e Fonte Azul não houve efeito nem de doses nem da adição de adjuvantes na ação do herbicida.

No entanto, deve-se considerar que no momento da aplicação dos tratamentos a aveia- 
preta encontrava-se em estádio vegetativo inicial, quando evidencia alta sensibilidade ao glyphosate. Com isso, a dose herbicida pode ter sido excessiva (270 g/ha i.a.) para controlar a espécie nesse estádio. Assim, o efeito antagônico sobre a ativida de do herbicida pode ter ocorrido, mas ter sido mascarado pelo excesso de produto ou pela sensiblidade da aveia-preta, fato que pode não ocorrer em espécies que apresentem maior tolerância ao herbicida ou pela própria aveia quando essa encontrar-se em estádios mais avançados de desenvolvimento. Além disso, as condições de ambiente durante as aplicações herbicidas, umidade relativa $78 \%$ e temperatura $23{ }^{\circ} \mathrm{C}$, foram consideradas favoráveis para absorção do herbicida. Isso pode ter favorecido a ação do herbicida, fato que pode não ocorrer em aplicações sob condições de estresse, umidade relativa menor que $65 \%$, provocando resposta difere nciada.

Outro fator de importância refere-se à concentração de sais e aos tipos de sais presentes nessas águas. A presença de sais nas águas testadas pode ter sido em níveis inferiores aos teores encontrados em outros locais, ou os sais presentes não se constituírem naqueles com maior efeito antagônico ao glyphosate. Isso poderia explicar a falha em se constatar efeitos negativos das águas minerais testadas, sobre a atividade do glyphosate, em comparação à água destilada, fato verificado por outros pesquisadores (Buhler \& Burnside, 1983b; Mervosh \& Balke, 1991; Nalewaja \& Matysiak, 1993b; Nalewaja et al., 1994), e também a falta de efeito sinérgico pela adição dos adjuvantes.

No entanto, constatou-se que o ácido sulfúrico foi eficiente em reduzir o $\mathrm{pH}$ da calda (Tabela 3). Nos tratamentos contendo glyphosate e mais ácido sulfúrico o $\mathrm{pH}$ posicionou-se entre 2,2 e 2,6. Essa faix a de $\mathrm{pH}$ está distante daquela considerado como ideal, ou seja, $\mathrm{pH}$ próximo ao valor $\mathrm{pK}$ do herbicida, que é o valor do $\mathrm{pH}$ onde aproximadamente $50 \%$ das moléculas do herbicida estarão na forma dissociada e os outros $50 \%$ na forma não dissociada. $\mathrm{O}$ valor $\mathrm{pK}$ ácido (pKa) do glyphosate, forma isopropilamina, é 5,6 (WSSA, 1994). Conforme enfatizado por Wanamarta \& Penner (1989) e Liebl et al. (1992), o valor ideal do $\mathrm{pH}$ da calda é aquele próximo ao do $\mathrm{pKa}$ do herbicida. Assim, o valor do $\mathrm{pH}$ da calda situou-se abaixo do pKa do herbicida, pode ter causado efeito negativo na atividade do herbicida.

A adição de sulfato de amônio reduziu o $\mathrm{pH}$ dos diferentes tipos de águas em teste, a valores situados entre 6,5 e 7,1, conforme a quantidade adicionada. Já foi relatado que o sulfato de amônio reduz o pH da calda (Gronwald et al, 1993; Liebl et al., 1992). Desse modo, o sulfato de amônio é eficiente em baixar o pH, necessitando-se apenas determinar as quantidades necessárias para corrigir o $\mathrm{pH}$ até valores próximos do pKa do herbicida. Contudo é conhecido que a adição de quantidades de sulfato de amônio acima de 9,7 kg/ha diminue a atividade do glyphosate (Salisbury et al., 1991). Dessa forma, a utilização do ácido seria desnecessária .

$\mathrm{O}$ efeito do herbicida glyphosate em reduzir o $\mathrm{pH}$ das águas mostrou-se considerável. Nas concentrações de apenas 0,125 e de $0,25 \%$, o $\mathrm{pH}$ da calda contendo águas minerais baixou, de valores acima de 9, para uma faixa entre 5,5 e 6,7. Já para 0,$5 ; 1$ e, $2 \%$ de concentração herbicida, o $\mathrm{pH}$ reduziu-se para valores entre 4,2 e 5,0. Para concentrações similares do herbicida sulfosate, o pH baixou para uma faixa entre 3,8 e 4,5; evidenciando-se, assim, efeitos equivalentes desses herbicidas sobre o $\mathrm{pH}$ de águas minerais (Tabela 3).

$\mathrm{O}$ efeito desses herbicidas sobre o $\mathrm{pH}$ da calda, quando se utilizou água destilada como diluente, foi maior do que o exercido sobre as demais águas. $\mathrm{O}$ valor final do $\mathrm{pH}$ da calda, com água destilada, foi menor do que nos outros casos. Isto demonstra um efeito diferencial do herbicida sobre a água destilada, constatando-se que seu $\mathrm{pH}$ foi reduzido a níveis inferiores àqueles das águas minerais. Contudo, o pH inicial das águas foi 
diferente; enquanto o das águas minerais situou-se acima de 9, o pH da água destilada era de apenas 5,3. Essa diferença pode ser responsável pelas variações encontradas. A mesma tendência foi verificada quando se comparam os valores de $\mathrm{pH}$ das águas ao se adicionar herbicida sulfosate, sulfato de amônio e/ou ácido sulfúrico.

Verificou-se que o $\mathrm{pH}$ da calda baixou para valores próximos a 5 quando se adicionou herbicida, para próximo de 7 quando se adicionou sufato de amônio e, para próximo de 2. quando se adicionou ácido sulfúrico. Já quando se adicionou o herbicida mais sulfato de amônio o pH baixou para valor próximo de 5. Com isso, evidencia-se que somente o acréscimo do herbicida por si só é capaz de baixar suficientemente o $\mathrm{pH}$ da calda, demonstrando ser desnecessário adição de ácido ou de sulfato de amônio com tal objetivo. Vale lembrar ainda que o ácido sulfúrico e o sulfato de amônio reagem com os sais presentes na solução, imobilizando-os (Wanamarta \& Penner, 1989). Essa seria outra utilidade desses adjuvantes; com isso, águas contendo altos teores de sais os teriam imobilizados e, assim, evitar-se-ia a complexação desses sais com as moléculas do herbicida. Além disso, existem referência de que o sulfato de amônio combina-se com a molécula herbicida, originando compostos com maior eficiência do que a molécula original (Nalewaja \& Matysiak, 1993a).

Os resultados permitem concluir que, para as doses herbicidas testadas, não se constatou qualquer ação negativa do $\mathrm{pH}$ original ou dos sais presentes nas águas minerais usadas como diluentes de glyphosate. Para plantas de aveiapreta no estádio de cinco a seis folhas, dose de $270 \mathrm{~g} / \mathrm{ha}$ i.a. do herbicida, misturado a qualquer dessa águas, é suficiente para propiciar controle superior a $98 \%$, dispensando o uso de sulfato de amônio e/ou de ácido sulfúrico na calda herbicida.

\section{LITERATURA CITADA}

AHMADI, M.S., HADERLIE, L. C., WICKS, G. A. O. Effect of growth stage and water stress on barnyardgrass (Echinochloa crus-galli) control and on glyphosate absorption and translocation. Weed Sci., v.28, n.3, p.277282, 1990.

BRYSON, C.T., HANKS, J.E., WILlS, G.D. Purple nutsedge (Cyperus rotundus) control in reduced-tillage cotton (Gossypium hirsutum L.) with low-volume technology. Weed Technol., v.8, n.1, p.28-31, 1994.

BUHLER, D.D., BURNSIDE, O.C. Effect of spray components on glyphosate toxicity to annual gras ses. Weed Sci., v.31, n.1, p.124-130, 1983a.

BUHLER, D.D., BURNSIDE, O.C. Effect of water quality, carrier volume, and acid on glyphosate phytotoxicity. Weed Sci., v.31, n.2, p.163-169, 1983 b.

CARLSON, K.L., BURNSIDE, O.C. Comparative phytotoxicity of glyphosate, SC-0224, SC0545, and HOE-00661. Weed Sci., v.32, n.6, p.841-844, 1984.

GR ONWALD, J. W., JOURDAN, S. W., WY SE, D. L., SOMERS, D. A., MAGNUS SON, M. U. Effect of ammonium sulfate on absorption of imazethapy $r$ by quackgrass (Elytrigia repens) and maize (Zea mays) cell suspension cultures. Weed Sci., v.41, n. 3, p.325-334, 1993 .

LEIF III, J.W., OELKE, E.A. Effects of glyphosate and surfactant concentrations on giant burseed (Sparganium eurycarpum) control with a ropewick applicator. Weed Technol., v.4, n.3, p.625-630, 1990.

Planta Daninha, v. 15, n. 2, 1997. 
LIEBL, R. A., ZEHR, U. B., TEYKER, R. H. Influence of nitrogen form on extracellular $\mathrm{pH}$ and bentazon uptake by cultured soybean (Glycine max) cells. Weed Sci., v.40, n. 3, p. 418-423,1992.

McCORMICK, R.W. Effects of $\mathbf{C o}_{2}, \mathbf{N}_{2}$, air and nitrogen salts on spray solution $\mathrm{pH}$. Weed Technol., v.4. n.4, p.910-912, 1990.

McMULLAN, P. M. Grass herbicide efficacy as influenced by adjuvants, spray solution $\mathrm{pH}$, and ultraviolet light. Weed Technol., v.10, n.1, p.72-77, 1996.

MERVOSH, T.L., BALKE, N.E. Effects of calcium, magnesium, and phosphate on glyphosate absorption by cultured plant cells Weed Sci., v.39, n.3, p.347-353. 1991.

NALEWAJA, J.D., MATYSIAK, R. Spray carrier salts affect he rbicide toxicity to kochia (Kochia scoparia). Weed Technol., v.7, n.1, p.154-158, 1993a.

NALEWAJA, J.D., MA TYS IAK, R. Op ti mi zing adjuvants to overcome glyphosate antagonistic salts. Weed Technol., v.7, n.2, p.337-342, 1993 b.

N A L E W A J A, J . D ., M A T Y S I A K, R ., SZELEZNIAK, E. F. Se thoxydin response to spray carrier chemical properties andenvironment. Weed Technol., v. 8, n.3, p.591-597, 1994.
S A L IS B UR Y, C. D., CHANDLER，J . M., MERKLE, M.G. Ammonium sulfate en hancement of glyphosate and SC-0224 control of Johsongrass (Sorghum halepense). Weed Technol., v.5, n.1, p.18-21, 1991.

SANDBERG, C.L., MEGGITT, W.F., PENNER, D. Effect of diluent volume and calcium on glyphosate phytotoxicity. Weed Sci., v.26, n.5, p.476-479, 1978.

SHERRICK, S.L., HOLT, H.A., HESS, F.D. Effects of adjuvants and environment during plant development on glyphosate absorption and translocation in field bindweed (Convolvulus arvensis). Weed Sci., v.34, n.6, p.811-816, 1986.

THELEN, K. D., JACKSON, E. P., PENNER, D. The basis for hard-water antagonism of glyphosate activity. Weed Sci., v.43, n.4, p.541-548, 1995.

WANAMARTA, G., PENNER D. Foliar absorption of herbicides. Review Weed Sci., v.4, p.215-232, 1989.

WILLS, G.D., McWHORTER, C.G. Effect of inorganic salts on the toxicity and translocation of glyphosate and MSMA in purple nutsedge (Cyperus rotundus). Weed Sci., v.33, n.6, p.755-761, 1985.

WSSA. Herbicide handbook, 7.ed., 1994, 352p. 